\title{
LA EMPRESA ESCLAVISTA DE DON PEDRO DE LA BARRERA (1611): UNA APORTACIÓN AL ESTUDIO DE LA TRATA LEGAL DE INDIOS EN CHILE ${ }^{1}$
}

\author{
José Manuel DíAZ BLANCO \\ Universidad de Sevilla
}

\begin{abstract}
RESUMEN: Este trabajo analiza un pleito judicial conservado en el Archivo de Indias que aporta datos desconocidos y de gran interés para la compresión del comercio esclavista de población indígena en el Chile del siglo XVII. Aquel proceso enfrentó a Hernando Machado, fiscal de la Audiencia de Chile, con don Pedro de la Barrera y su familia y la documentación que generó aporta numerosas noticias sobre la mercancía humana, los vendedores, los compradores, los mercados, el impacto de la esclavitud sobre los pueblos indígenas, etc.
\end{abstract}

PALABRAS CLAVE: Esclavitud de indios, Chile (siglo XVII), sociedad colonial de Valdivia y Osorno, familia Barrera, Hernando Machado.

ABSTRACT: This paper analyzes a court case found in the Archive of the Indies which presents previously unknown evidence and is of much importance to understanding the Indian slave trade in Chile during the seventeenth century. This court case pitted Hernando Machado, prosecutor of the Audiencia of Chile, against Pedro de la Barrera and his family and the documentation that was generated includes a large amount of information about human trafficking, the sellers, the buyers, the markets, the impact of slavery on the Indigenous villages, etc.

KEYWORDS: Indian Slavery, Chile (seventeenth century), colonial society in Valdivia and Osorno, the Barrera family, Hernando Machado.

Chile fue uno de los pocos territorios de la América Colonial en los que, durante algún tiempo, la esclavitud de los nativos tuvo curso legal. La excepcionalidad de esta circunstancia invita a suponer que haya gozado de un amplio acervo de publicaciones, pero desgraciadamente no ha conocido tal suerte. Álvaro Jara Hanke se propuso estudiarla, pero su Guerra y sociedad en Chile apenas traspasó el límite de la publicación de la cédula de esclavitud de 1608. Después, no ha habido más que un muy reducido número de estudios entre los que merece destacarse el de

\footnotetext{
${ }^{1}$ Recibido el 16 de febrero de 2011. Aceptado en el Consejo de 8 de noviembre de 2011.
} 
Walter Hanisch, que se ha interesado por la materia desde una perspectiva fundamentalmente jurídica e intelectual ${ }^{2}$. Por supuesto, no cabe entender esta poquedad como fruto de desinterés hacia la cuestión, sino como consecuencia, entre varios factores de orden diverso, de una pobreza de fuentes casi absoluta: si existe una veta documental que permita reconstruir información en serie sobre aquel fenómeno histórico, aún no ha sido hallada por historiador alguno.

En este contexto tan negativo, me parece interesante dar a conocer la sobresaliente información que guarda un pleito judicial sobre esclavos, dirimido en la Real Audiencia de Chile y el Consejo de Indias entre 1611 y 1619. Este expediente encierra la historia de una empresa esclavista de cierta importancia, amparada por el maestre de campo don Pedro de la Barrera Chacón, quien desde el gobierno político y militar de Chiloé promocionó diversas malocas a los territorios de Valdivia y Osorno en las que se capturaron hombres que, en muchos casos, fueron enviados al Chile central en 1611 para ser vendidos como esclavos. En Santiago, el fiscal de la Audiencia Hernando Machado tuvo conocimiento de su desgracia y entendió que la operación de Barrera excedía en mucho el marco legal establecido por la cédula de la esclavitud. En consecuencia, se querelló contra él, dando lugar a un pleito que llegó a la jurisdicción del Consejo en $1616^{3}$.

Gracias a las pruebas documentales que aportaron ambas partes, podemos conocer muchos detalles de los hombres que se vieron implicados en aquellos acontecimientos. Son especialmente ricos tres documentos: una primera relación sin título, una Memoria de la gente e indios que vinieron en los tres navios que vinieron de arriba de la ciudad de Chiloé y, finalmente, un repertorio de auténticas patentes de esclavitud de indios americanos del siglo XVII ${ }^{4}$. Gran parte de la información que se colige de ellos queda unificada en el siguiente cuadro:

2 JARA HANKE, Á. (1981 [1961]. Guerra y sociedad en Chile. La transformación de la guerra de Arauco y la esclavitud de los indios, Santiago: Editorial Universitaria. HANISCH, W. (1981). «Esclavitud y libertad de los indios de Chile, 1608-1696». Historia, 16, pp. 5-65. Siempre puede encontrarse alguna referencia aislada, como la de Retamal ÁviLA, J. (2006). «Economía y sociedad en el Maule sur en el siglo XVII». En ibid. (coord.). Estudios coloniales IV, Santiago: Universidad Andrés Bello, pp. 77-145, que menciona los 27 esclavos indígenas que en 1674 poseía doña Mencía de Mieres. Más recientemente, Obregón ItURRA, J. P. y Zavala CePeda, J. M. (2009). «Abolición y persistencia de la esclavitud indígena en Chile Colonial: estrategias esclavistas en la frontera araucano-mapuche». Memoria americana, 17-1, pp. 7-31.

${ }^{3}$ AGI, Escribanía, leg. 928 b.

${ }^{4}$ Ibíd., fols. 2, 40r-43r y 85-102 (con copia en fols. 54r-58v). 
La empresa esclavista de don Pedro de la Barrera (1611): una aportación al estudio de la trata legal de...

\begin{tabular}{|c|c|c|c|c|c|c|c|c|}
\hline 1 & 2 & 3 & 4 & 5 & 6 & 7 & 8 & 9 \\
\hline Jorge / Ayllán (cacique) & & $\mathrm{M}$ & $\mathrm{C}$ & Rulo & Jorge & Gaspar Verdugo & & \\
\hline Inés & & $\mathrm{E}$ & $\mathrm{C}$ & " & , & I & & \\
\hline Perico & & $\mathrm{H}$ & $\mathrm{C}$ & ", & " & " & & \\
\hline Juan & & $\mathrm{H}$ & $\mathrm{C}$ & " & " & " & & \\
\hline Francisco Muymil & 28 años & M & $\mathrm{C}$ & " & Ayllán & " & $\begin{array}{l}\text { Antonio } \\
\text { Méndez }\end{array}$ & $\begin{array}{l}\text { Juan } \\
\text { Pérez }\end{array}$ \\
\hline Isabel & 25 años & $E$ & $\mathrm{C}$ & "' & "' & $"$ & " & " \\
\hline Diego & "de pecho" & $\mathrm{H}$ & $\mathrm{C}$ & " & ", & ", & ", & " \\
\hline Guele & & $\mathrm{A}$ & $\mathrm{C}$ & " & Ayllán & “ & “ & " \\
\hline Miguel Luculante & 40 años & M & $\mathrm{C}$ & Rulo & Ayllán & “ & “ & " \\
\hline Isabel & 18 años & $\mathrm{E}$ & $\mathrm{C}$ & " (n. Maibén) & " & " & $"$ & “ \\
\hline & & $\mathrm{H}$ & & Rulo & " & $"$ & " & " \\
\hline Hernando & 26 años & M & $\mathrm{C}$ & " & " & " & " & “ \\
\hline Bárbola & $\begin{array}{l}28 \text { años } \\
\text { "de pecho" }\end{array}$ & $\begin{array}{l}E \\
H\end{array}$ & $\mathrm{C}$ & ", & ", & " & " & “ \\
\hline & 1 año & $\mathrm{H}$ & & " & " & " & " & " \\
\hline Marcela & & $\mathrm{A}$ & $\mathrm{C}$ & " & " & $"$ & " & " \\
\hline Hernando / Caniu & 26 años & M & I & ", & ", & " & ", & " \\
\hline Marcela & 28 años & $\mathrm{E}$ & & " & " & " & " & " \\
\hline Úrsula & 1 año & $\mathrm{H}$ & & ", & " & " & " & “ \\
\hline Alonso Ibumbue & 30 años & $\mathrm{M}$ & $\mathrm{C}$ & Rulo & Ayllán & Gaspar Verdugo & " & “ \\
\hline Agustina & 30 años & E & $\mathrm{C}$ & "' & " " & " " & $"$ " & " \\
\hline Cristóbal / Niagueno & $\begin{array}{l}\text { "de pecho" } \\
35 \text { años }\end{array}$ & $\begin{array}{l}\mathrm{H} \\
\mathrm{M}\end{array}$ & $\mathrm{C}$ & Peulla & Cave & Mateo Pizarro & " & ", \\
\hline Leonor / Luplul & 24 años & $\mathrm{E}$ & $\mathrm{C}$ & " & "ente & MVteo izano & " & " \\
\hline Águeda & "de pecho" & $\mathrm{H}$ & $\mathrm{C}$ & ", & “ & " & ” & “ \\
\hline Bartolomé & 33 años & M & $\mathrm{C}$ & Colotue & D. Cristóbal & Aróstegui & $"$ "' & " \\
\hline Ana & 25 años & $\mathrm{E}$ & $\mathrm{C}$ & , & ". & ". & ", & " \\
\hline Dieguillo & 1 año & $\mathrm{H}$ & $\mathrm{C}$ & ", & ", & " & ", & ", \\
\hline Alonso & & M & $\mathrm{C}$ & & & $\begin{array}{l}\text { "Sancho" ¿de las } \\
\text { Cuevas? }\end{array}$ & & \\
\hline Jerónima & & $\mathrm{E}$ & $\mathrm{C}$ & & & cacras. & & \\
\hline $\begin{array}{l}\text { Martín } \\
\text { Elvira }\end{array}$ & 18 años & $\begin{array}{l}\mathrm{M} \\
\mathrm{E}\end{array}$ & $\begin{array}{l}\mathrm{C} \\
\mathrm{C}\end{array}$ & $\begin{array}{r}\text { Puyehue } \\
\text {,. }\end{array}$ & Bartolomé & "Lope" , & & \\
\hline Domingo Maichen & 30 años & M & $\mathrm{C}$ & Pudecha & Deomallanca & Juan Bello & $\begin{array}{l}\text { Antonio } \\
\text { Méndez }\end{array}$ & $\begin{array}{l}\text { Juan } \\
\text { Pérez }\end{array}$ \\
\hline Úrsula & 26 años & $\mathrm{E}$ & $\mathrm{C}$ & ", & ", & " & , & \\
\hline Luis & 3 años & $\mathrm{H}$ & $\mathrm{C}$ & "' & " & " & “ & “ \\
\hline Frasquilla & "de pecho" & $\mathrm{H}$ & $\mathrm{C}$ & " & " & " & $"$ & $"$ \\
\hline Martín Naynam & 30 años & M & $\mathrm{C}$ & Poroa & Mallonaquel & Juan Aguilera & “ & " \\
\hline Ana & 35 años & $\mathrm{E}$ & $\mathrm{C}$ & " & "1 & ". & " & " \\
\hline Juana & 2 años & $\mathrm{H}$ & $\mathrm{C}$ & " & ", & " & " & " \\
\hline $\begin{array}{l}\text { Pedro Quintoparay } \\
\text { (cacique) }\end{array}$ & 40 años & M & $\mathrm{C}$ & Pudeto & $\begin{array}{l}\text { Pedro } \\
\text { Quintoparay }\end{array}$ & Álvaro Figueroa & $\begin{array}{l}\text { Mtnez. } \\
\text { Vergara }\end{array}$ & \\
\hline María & & $\mathrm{E}$ & $\mathrm{C}$ & "' & " & " & " & \\
\hline Leonor & 8 años & $\mathrm{H}$ & & & " & " & " & \\
\hline Petrona & 2 meses & $\mathrm{H}$ & $\mathrm{C}$ & " & " & " & " & \\
\hline Gonzalo Cutamante & 20 años & & $\mathrm{C}$ & " & " & " & " & \\
\hline Felipe Coneante & 30 años & $\mathrm{M}$ & $\mathrm{C}$ & " & " & " & " & \\
\hline Inés & 40 años & $\bar{E}$ & $\mathrm{C}$ & $"$ " & $"$ " & " & " & \\
\hline Cristóbal & 14 años & $\mathrm{H}$ & $\mathrm{C}$ & ", & ", & " & ", & \\
\hline Juan Huechull-huaquin & 34 años & M & $\mathrm{C}$ & ", & ", & " & " & \\
\hline Isabel & 25 años & $\mathrm{E}$ & $\mathrm{C}$ & ", & ", & " & “ & \\
\hline Luisito & 9 años & $\mathrm{H}$ & $\mathrm{C}$ & ” & “ & “ & “ & \\
\hline Panchillo & 4 años & $\mathrm{H}$ & $\mathrm{C}$ & " & " & " & " & \\
\hline Jerónimo Ellehuenanco & 34 años & M & $\mathrm{C}$ & " & " & " & " & \\
\hline Jerónima & & $\mathrm{E}$ & $\mathrm{C}$ & " & " & " & “ & \\
\hline Antonillo & 6 años & $\mathrm{H}$ & $\mathrm{C}$ & " & " & " & " & \\
\hline Francisco Coleabun & 30 años & M & $\mathrm{C}$ & “ & “ & " & " & \\
\hline Ana & 32 años & $\mathrm{E}$ & $\mathrm{C}$ & " & " & " & " & \\
\hline Rodrigo & 5 años & $\mathrm{H}$ & $\mathrm{C}$ & ", & ", & " & ", & \\
\hline Ventura & 3 años & $\mathrm{H}$ & $\mathrm{C}$ & " & " & “ & “ & \\
\hline & 8 días & $\mathrm{H}$ & & ", & ", & " & “ & \\
\hline Rodrigo Huallmiahui & 25 años & $\mathrm{M}$ & $\mathrm{C}$ & “ & “ & " & “ & \\
\hline Isabel & 28 aก̃os & $\mathrm{E}$ & $\mathrm{C}$ & $"$ & $"$ & " & " & \\
\hline Juana & 1 año & $\mathrm{H}$ & $\mathrm{C}$ & " & " & " & " & \\
\hline $\begin{array}{l}\text { Gaspar } \\
\text { huechun }\end{array}$ & 26 años & M & $\mathrm{C}$ & " & " & " & ", & \\
\hline Isabel & 45 años & $\mathrm{E}$ & $\mathrm{C}$ & " & " & " & " & \\
\hline María & 6 años & $\mathrm{H}$ & $\mathrm{C}$ & ", & ", & " & " & \\
\hline Sebastián Pidcunmapo & 45 años & & $\mathrm{C}$ & "' & "' & "" & "" & \\
\hline
\end{tabular}




\section{José Manuel Díaz Blanco}

\begin{tabular}{|c|c|c|c|c|c|c|c|c|}
\hline $\begin{array}{l}\text { Naupayante } \\
\text { Domingo Neculpangue } \\
\text { Isabel } \\
\text { Juanillo }\end{array}$ & 2 años & $\begin{array}{l}M \\
\mathrm{E} \\
\mathrm{H}\end{array}$ & $\begin{array}{l}\mathrm{C} \\
\mathrm{C} \\
\mathrm{C}\end{array}$ & $\begin{array}{l}\text { Cullull } \\
\text { (Purailla) } \\
\text { Manque-tecau } \\
\text {,, } \\
\text {,- }\end{array}$ & $\begin{array}{l}\text { Neyco- } \\
\text { pangue }\end{array}$ & $\begin{array}{c}\text { Fco.Santisteban } \\
\text { Sancho Cuevas } \\
\text { ״, }\end{array}$ & $\begin{array}{l}{ }^{\prime} \\
\text {, } \\
\text {, }\end{array}$ & $\begin{array}{l}\text { Alonso } \\
\text { Campo }\end{array}$ \\
\hline $\begin{array}{l}\text { Luisa } \\
\text { Francisco } \\
\text { Ana }\end{array}$ & "pequeñito & $\begin{array}{l}\mathrm{H} \\
\mathrm{M} \\
\mathrm{E} \\
\mathrm{H} \\
\mathrm{H}\end{array}$ & $\begin{array}{l}\mathrm{C} \\
\mathrm{C} \\
\mathrm{C} \\
\mathrm{C} \\
\mathrm{C}\end{array}$ & " & & $\begin{array}{c}\text { Gonzalo Díaz } \\
\text { ". } \\
\text {." } \\
\text {." }\end{array}$ & " & \\
\hline $\begin{array}{l}\text { Martín Caullamante } \\
\text { Isabel } \\
\text { Juan } \\
\text { Isabel }\end{array}$ & $\begin{array}{l}30 \text { años } \\
40 \text { años }\end{array}$ & $\begin{array}{l}\mathrm{H} \\
\mathrm{M} \\
\mathrm{E} \\
\mathrm{M} \\
\mathrm{E}\end{array}$ & $\begin{array}{l}\mathrm{C} \\
\mathrm{C} \\
\mathrm{C}\end{array}$ & Tubquen-caví & $\begin{array}{c}\text { Nachicuo } \\
\text {,. }\end{array}$ & $\begin{array}{l}\text { Tomás Núñez } \\
\text { Miguel Sánchez } \\
\text { ״, }\end{array}$ & $\begin{array}{l}\text { Mtnez. } \\
\text { Vergara }\end{array}$ & \\
\hline $\begin{array}{l}\text { Sancho } \\
\text { Luis } \\
\text { Sebastián } \\
\text { Marcela } \\
\text { Francisca }\end{array}$ & 3 años & $\begin{array}{l}\mathrm{H} \\
\mathrm{H} \\
\mathrm{M} \\
\mathrm{E} \\
\mathrm{H}\end{array}$ & $\begin{array}{l}\mathrm{C} \\
\mathrm{C} \\
\mathrm{C}\end{array}$ & & & $\begin{array}{c}" \\
\text { Julián Ordóñez } \\
\text { ". } \\
\text { ". }\end{array}$ & $\begin{array}{r}\text { Mtnez. } \\
\text { Vergara } \\
\text {., }\end{array}$ & $\begin{array}{c}\text { G.Lillo } \\
\text {, } \\
\text {, }\end{array}$ \\
\hline $\begin{array}{l}\text { Diego } \\
\text { Sebastián }\end{array}$ & & $\begin{array}{l}\mathrm{H} \\
\mathrm{M} \\
\mathrm{H} \\
\mathrm{H} \\
\mathrm{H}\end{array}$ & $\begin{array}{l}\text { C } \\
\mathrm{C} \\
\mathrm{C} \\
\mathrm{C} \\
\mathrm{C}\end{array}$ & & & $\begin{array}{c}\text { "' } \\
\text { Rodrigo Rojas } \\
\text {., } \\
\text {., }\end{array}$ & " & \\
\hline $\begin{array}{l}\text { D. Felipe } \\
\text { Juana } \\
\text { Rodrigo } \\
\text { Isabel }\end{array}$ & & $\begin{array}{l}M \\
E \\
H \\
M \\
E\end{array}$ & $\begin{array}{l}\text { C } \\
\mathrm{C} \\
\mathrm{C} \\
\mathrm{C} \\
\mathrm{C}\end{array}$ & & & $\begin{array}{c}\text { Fco. Garcés } \\
\text { ", } \\
\text {,. } \\
\text { ", }\end{array}$ & & \\
\hline $\begin{array}{l}\text { Sebastián } \\
\text { Gonzalo } \\
\text { Sebastián } \\
\text { Guele } \\
\text { Frasquillo }\end{array}$ & & $\begin{array}{l}\mathrm{H} \\
\\
\mathrm{Ma} \\
\mathrm{H}\end{array}$ & $\begin{array}{l}\mathrm{C} \\
\mathrm{C} \\
\mathrm{C}\end{array}$ & & & $\begin{array}{l}\text { Cortés Ojeda } \\
\text { Cortés Ojeda }\end{array}$ & & \\
\hline $\begin{array}{l}\text { Alonso } \\
\text { Frasquillo } \\
\text { Pedro }\end{array}$ & & $\begin{array}{l}M \\
E \\
H \\
H\end{array}$ & $\begin{array}{l}\mathrm{C} \\
\mathrm{C} \\
\mathrm{C} \\
\mathrm{C} \\
\mathrm{C}\end{array}$ & & & & & \\
\hline $\begin{array}{l}\text { Luis } \\
\text { Elena } \\
\text { Ana } \\
\text { Rulo } \\
\text { Jerónima }\end{array}$ & 6 años & $\mathrm{Ch}$ & $\begin{array}{l}\text { I } \\
\text { C }\end{array}$ & $\begin{array}{c}\text { Purailla } \\
\text {,. } \\
\text { ', } \\
\text { Reloncaví }\end{array}$ & & & $\begin{array}{r}\text { Alonso } \\
\text { Pineda } \\
\text { ", } \\
\text { ". } \\
\text { ", }\end{array}$ & \\
\hline $\begin{array}{l}\text { Francisca } \\
\text { Elauma } \\
\text { Esperanza } \\
\text { Gaspar }\end{array}$ & "cría" & $\begin{array}{l}\mathrm{Ma} \\
\mathrm{H}\end{array}$ & $\begin{array}{l}\mathrm{C} \\
\mathrm{I} \\
\mathrm{I} \\
\mathrm{C} \\
\mathrm{C}\end{array}$ & $\begin{array}{l}\text { Colotue } \\
\text { Pudecha }\end{array}$ & & & $\begin{array}{l}" \\
\text { ", } \\
\text {. } \\
\text { ", } \\
\text { ", }\end{array}$ & \\
\hline $\begin{array}{l}\text { Lorenza } \\
\text { Angelina } \\
\text { Petrona } \\
\text { Cullue }\end{array}$ & "cría" & $\begin{array}{l}\mathrm{Ma} \\
\mathrm{H}\end{array}$ & $\begin{array}{l}\mathrm{C} \\
\mathrm{C}\end{array}$ & 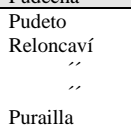 & & & $\begin{array}{l}" \\
\text { ", } \\
\text { ", } \\
\text { ", }\end{array}$ & \\
\hline $\begin{array}{l}\text { Francisco } \\
\text { María } \\
\text { María } \\
\text { Beatriz } \\
\text { Anita }\end{array}$ & "muchacho & $\mathrm{Ch}$ & $\begin{array}{l}\text { C } \\
\mathrm{C} \\
\mathrm{C} \\
\mathrm{C} \\
\mathrm{C}\end{array}$ & $\begin{array}{l}\text { Pudeto } \\
\text { Purailla } \\
\text { Chanreca } \\
\text { Colotue }\end{array}$ & & & $\begin{array}{c}\text { Fco. Andrea } \\
\text {,. } \\
\text {, } \\
\text {, }\end{array}$ & \\
\hline $\begin{array}{l}\text { Luisa } \\
\text { Francisco } \\
\text { Juana } \\
\text { Jorge } \\
\text { Agustina }\end{array}$ & "muchacho & $\begin{array}{l}\mathrm{Ch} \\
\mathrm{M}\end{array}$ & $\begin{array}{l}\mathrm{C} \\
\mathrm{C} \\
\mathrm{C} \\
\mathrm{C} \\
\mathrm{C}\end{array}$ & $\begin{array}{l}\text { Rulo } \\
\text { Osorno } \\
\text { Yocoligue }\end{array}$ & & & $\begin{array}{l}\text { "' } \\
\text { Bart. Ochoa } \\
\text { Juan Burgos } \\
\text { Juan Alanís } \\
\text { " }\end{array}$ & \\
\hline Sebastián & & $\mathrm{H}$ & $\mathrm{C}$ & " & & & $\begin{array}{l}\text { Marcos } \\
\text { Velín }\end{array}$ & $\begin{array}{l}\text { Jmo. } \\
\text { Peraza } \\
\text { Concepci } \\
\text { ón }\end{array}$ \\
\hline
\end{tabular}


La empresa esclavista de don Pedro de la Barrera (1611): una aportación al estudio de la trata legal de...

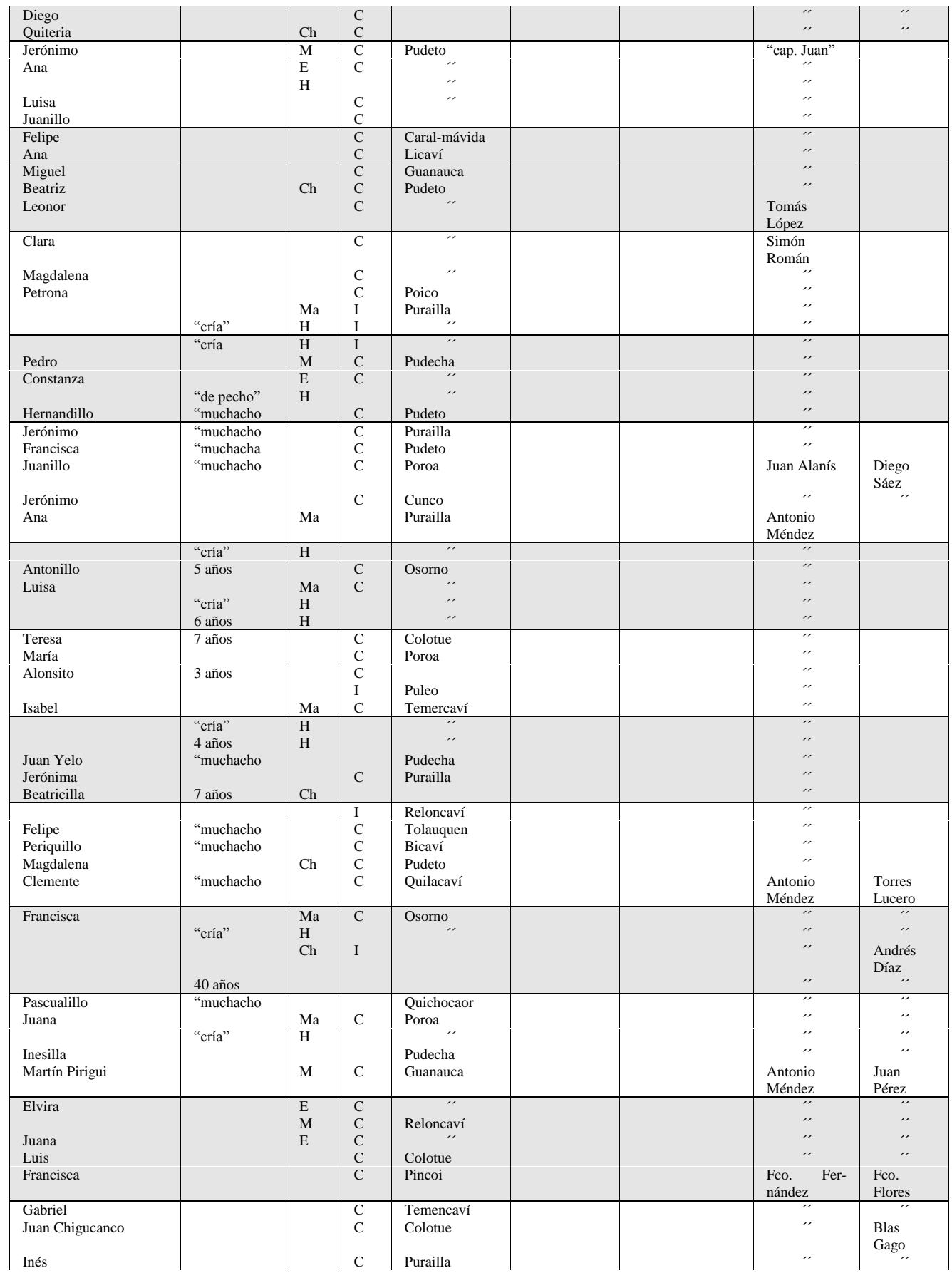




\section{José Manuel Díaz Blanco}

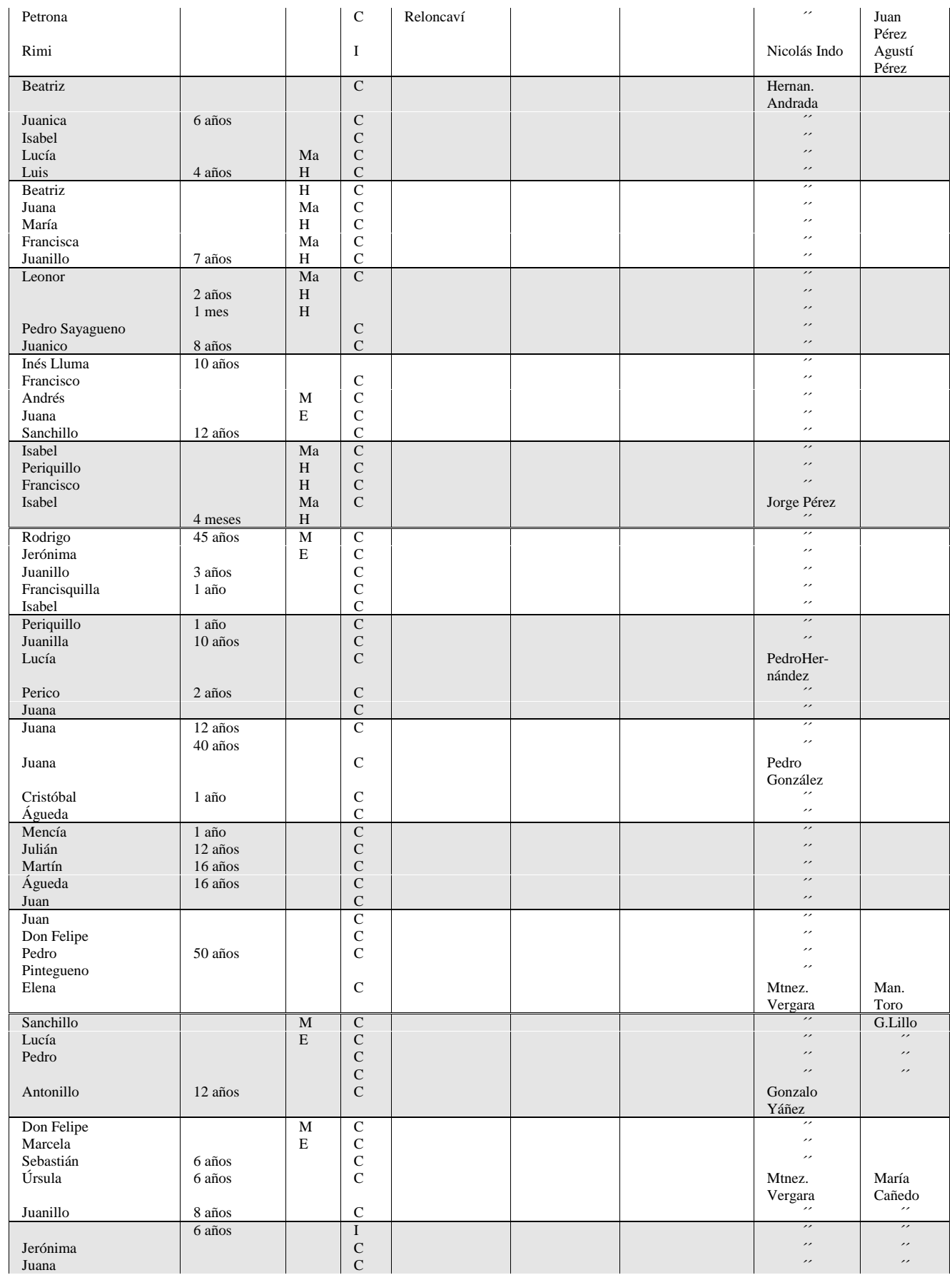




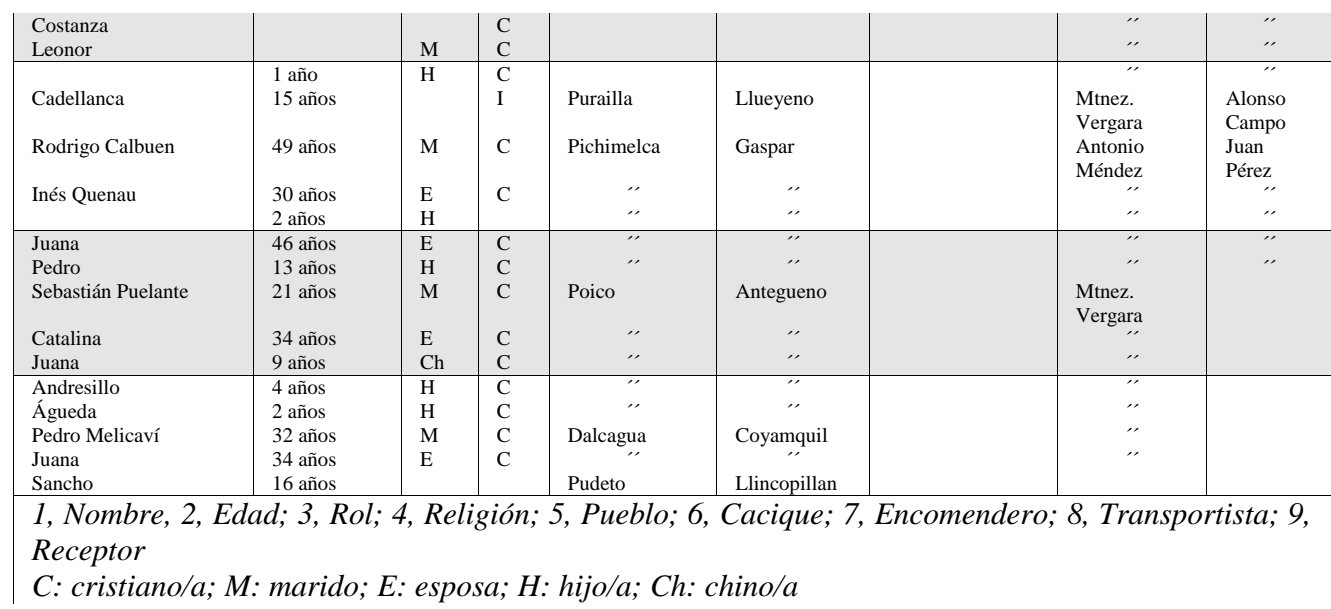

Más allá de la posibilidad, profundamente emocionante, de captar la individualidad de las personas que padecieron aquella lacra (y también de quienes la practicaron y se beneficiaron de ella), pueden observarse a simple vista rasgos y fenómenos de conjunto más relevantes. Con respecto al orden espacial, se percibe con claridad que los esclavos procedían, como no podía ser de otra forma, de una geografía limítrofe a Chiloé, centro de operaciones de don Pedro de la Barrera, aunque no siempre sea posible identificar los topónimos concretos que se citan ${ }^{5}$. Se trataba de un área periférica que se reveló como zona de captación de mercancía humana, que era posteriormente transportada hacia los mercados chilenos más importantes, ubicados entre Santiago y Concepción. Es posible incluso que desde allí los esclavos fuesen enviados a Perú, merced a la presencia de Juan Pérez de Urasandi, dueño de un barco que transportaba mercancías entre Chile y la capital del Virreinato, que aparece aquí recibiendo una cantidad muy considerable de piezas 6 .

Los datos del cuadro también nos permiten reconstruir el mundo de los afectados antes de convertirse en esclavos. La primera relación menciona 17 encomiendas antiguas con sus respectivos titulares, de los cuales hay 7 que no hemos logrado identificar, en algún caso por nuestra impericia, en algún otro por la parquedad del documento y quizás en otros porque mencione individuos de los que

${ }^{5}$ Recientemente ha escrito la historia de este espacio URBINA CARRASCO, M. X. (2009). La frontera de arriba en Chile Colonial. Interacción hispano-indígena en el área entre Valdivia y Chiloé e imaginario de sus bordes geográficos, 1600-1800, Valparaíso: Pontificia Universidad Católica de Valparaíso-DIBAM.

${ }^{6}$ Sobre él, véase AGI, Chile, leg. 41, n. 10. 
nada se sabía hasta ahora ${ }^{7}$. En cambio, existe la posibilidad de reconocer a otros de los encomenderos referidos: "Cortés de Ojeda", por ejemplo, es sin duda Francisco Cortés de Ojeda o, en todo caso, un descendiente muy directo suyo, tal como un hijo ${ }^{8}$; mientras que Rodrigo de Rojas es seguramente aquel a quien Tomás Thayer Ojeda cita como "don Rodríguez de Rojas". Se cuenta entre ellos a un vecino de Valdivia: Gaspar Verdugo ${ }^{10}$, pero la mayoría estuvo radicada en Osorno: los dos antes referidos, Francisco Garcés de Bobadilla ${ }^{11}$, Gonzalo Díaz Cabrera ${ }^{12}$, Francisco de Santisteban $^{13}$, Álvaro de Figueroa ${ }^{14}$ y Mateo Pizarro ${ }^{15}$, entre los cuales existieron en muchos casos lazos familiares bastante estrechos. Así, Pizarro fue el

${ }^{7}$ Más concretamente, puede detallarse que los dos encomenderos referidos únicamente por su nombre de pila -"don Lope", "don Sancho"...- son hoy difícilmente identificables. Pensamos que Julián Ordóñez y Tomás Núñez podrían tener alguna vinculación con el círculo de Jerónimo Núnez, aunque no lo podríamos asegurar ni mucho menos precisar en sus pormenores. Parece también fácil a primera vista relacionar a don Sancho de Cuevas (que quizás sea ese "don Sancho" antes mencionado) con la famosa familia encomendera Cuevas, pero, de ser así, el vínculo exacto se nos escapa completamente. Juan Bello podía también presentar algún tipo de cercanía con un Jerónimo Bello citado por Thayer, pero una vez más no hay forma de demostrarlo.

${ }^{8}$ THAYER OJEDA, T. (193). Formación de la sociedad chilena y censo de la población de Chile en los años de 1540 a 1565 con datos estadísticos, biográficos, étnicos y demográficos, 3 vols., Santiago: Universidad de Chile, I, p. 263, dice de él que llegó a Chile en la década de 1550, fue vecino de Valdivia y se contó entre los fundadores de Osorno, en cuyo cabildo ocupó diversos cargos. No da noticia alguna de su calidad de encomendero.

${ }^{9}$ Ibid., II, pp. 145-146: hijo de Diego de Rojas y Catalina de Pliego [¿Priego?]. Su padre intervino en la fundación de las ciudades australes, entre ellas Osorno, donde gozó de una encomienda que fue seguramente la que después heredaría Rodrigo. Estuvo casado en primeras nupcias con Catalina Ortiz de Caravantes y en segundas con Juana Cortés de Monroy.

${ }^{10}$ Ibid., III, pp. 363-364. Nacido en España en 1533. Pasó al Perú con el Marqués de Cañete en 1555 y después a Chile en 1565. En 1577 ya era encomendero de Valdivia, sobre una encomienda a la que seguramente pertenecieron los indios del expediente que aquí estudiamos. Estaba vivo en 1593, años por los que parece que pasó a Quito para combatir la rebelión de las alcabalas.

${ }^{11}$ Ibid., II, pp. 19-20, lo consigna como encomendero de Osorno en 1591 y afirma que era hijo de Juan Garcés de Bobadilla y doña Luisa Pizarro. Juan llegó a Chile con Diego García de Altamirano y participó en la fundación de todas las ciudades del sur, entre ellas Osorno, de la que fue uno de sus primeros encomenderos, en lo que Francisco le heredaría.

${ }^{12}$ Ibid., I, pp. 287-288: hijo de Jerónimo Díaz del Campo e Isabel de Cabrera. Thayer afirma que Jerónimo fue encomendero de Osorno y aún se hallaba vivo en 1587, aunque de Gonzalo no lo dice en ningún momento.

${ }^{13}$ Ibid., III, p. 220: natural de Úbeda, fue fundador y encomendero de Valdivia y luego encomendero de Osorno, donde tuvo cargos en el Cabildo.

${ }^{14}$ Ibid., I, pp. 344-345: hijo del cacereño Juan Figueroa Villalobos e Inés de Mendoza y Cimbrón. Nació en 1569, fue corregidor de Santiago y vecino encomendero de Osorno.

15 Ibid., III, pp. 90-91: fundador de Osorno o vecino desde muy temprana fecha. Thayer lo documenta allí entre 1558 y 1565 . Fue alcalde ordinario del Cabildo en 1571 y estaba vivo al menos en 1589. 
suegro de Juan Garcés de Bobadilla, padre de Francisco, pero también de María Garcés de Bobadilla, esposa a su vez de Álvaro de Figueroa.

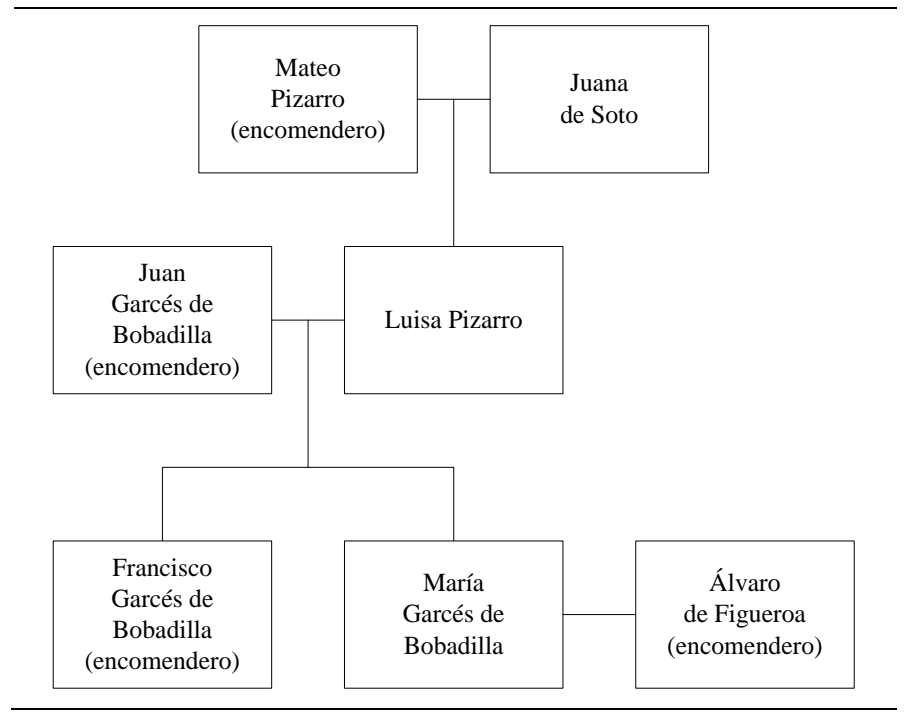

En definitiva, los individuos aislados que menciona la relación de este pleito parecen haber pertenecido a la pequeña élite provinciana que habitó Valdivia y, sobre todo, Osorno antes de su destrucción. Eran los fundadores de ambas ciudades o sus hijos; basaban su poder en el disfrute de estas encomiendas, el acceso a los cabildos y, presumiblemente, en la posesión de fincas rústicas; y emplearon tan notable endogamia familiar para conservar su preponderancia social, sellando alianzas entre las familias más encumbradas y absorbiendo en ellas a los recién llegados más prometedores.

Después de la rebelión de 1599, aquella estructura de poder basada en la encomienda desapareció y dejó libres los cacicazgos indígenas australes, de entre los que podemos identificar más de una decena de los que existieron a comienzos del siglo XVII y hasta reconstruir en algún caso su vinculación con las extintas encomiendas españolas. Un ejemplo importante es el del repartimiento de don Álvaro de Figueroa, que, sin duda, se correspondió o al menos incluyó el cacicazgo de don Pedro Quintoparay, del que en 1611 llegaron a Santiago como esclavos casi 40 individuos. Sin pretender relativizar las mezquindades que permitió la encomienda, parece que su efecto no fue necesariamente devastador en esta región. Dicho de otro modo, los cacicazgos existentes a mediados del siglo XVI, fueron encomendados en vecinos españoles como los que hemos visto, a quienes sus indios pagaron un tributo (teóricamente en dinero o especie, seguramente en 
trabajo total o parcialmente). Cuando medio siglo después los españoles huyeron escapando de la rebelión, los mismos cacicazgos siguieron existiendo sin ellos.

Eso sí, la posibilidad de contemplar "por dentro" estos cacicazgos nos enseña que la rebelión no permitió un retorno puro a la situación de 1550. Las cinco décadas del régimen de encomiendas no habían pasado en balde y dejaron su huella en la población huilliche, aún perceptible, por débil que fuese, después de la expulsión de los españoles. La más evidente se relaciona con el aparente cristianismo de la población, que, por supuesto, hay que relativizar mucho. Se puede observar en el gráfico que el número de indios registrados como infieles es minoritario, si bien no por ello puede suponerse que la evangelización de aquellas tierras se hallase muy avanzada. Tantos indios cristianos no son en puridad sino indios bautizados, ritual a partir del cual no es fácil suponer una estrecha observância, por su parte, de los preceptos de la Iglesia Católica. Pero, ¿puede suponerse por el contrario una completa ignorancia de ellos después del bautismo? En un nivel mucho más superficial que el de las creencias, podemos comprobar cómo los nombres cristianos, consecuencia secundaria del rito religioso, eran todavía recordados entre la población indígena una década después del estallido de la rebelión y a veces incluso se entrelazaban con los indígenas generando nomenclaturas seductoramente mestizas: Gonzalo Cutamante, Rodrigo Calbuen, Pedro Sayagueno... Teniendo esto en cuenta, ¿podría también sugerirse una paralela pervivencia de los dogmas prehispánicos progresivamente teñidos de Cristianismo? Parece razonable, aunque lamentablemente escasean las pruebas documentales que nos permitan corroborarlo.

Se observa en los cacicazgos otro elemento aparentemente relacionable con la cultura occidental: la estructura familiar, que, desmintiendo las invectivas de muchos discursos acerca del carácter polígamo de los nativos chilenos (supuesta razón de peso para no aceptar el mensaje de Cristo), presenta una arquitectura mononuclear y patriarcal. De entre todas las familias que este expediente permite reconstruir, sólo una se articula en torno a un esquema de poligamia, la del mencionado Rodrigo Calbuen, unido a Inés Quenau y a Juana, con cada una de las cuales tuvo al menos un hijo. Salvando esta excepción, todas las demás familias se componen de marido, mujer, una prole que rara vez supera los dos o tres hijos y, ocasionalmente, alguno de los abuelos. Era así incluso entre las familias de los caciques. La de Jorge, por ejemplo, cacique del cacicazgo encomendado en su día a Gaspar Verdugo, no incluía más que a su esposa Inés y a sus hijos Perico y Juan. O también la familia de Domingo Neculpangue, del pueblo de Licaví, perteneciente al cacicazgo de Manquetecau, antes en la encomienda de Sancho de las Cuevas, que no contaba más que con él, su mujer Isabel y sus hijos Juanillo y Luisa. 
Siendo esto claramente lo que indica la documentación, ¿puede suponerse que la monogamia huilliche se debiese a la predicación de los doctrineros y misioneros cristianos? Sin desestimar los influjos que pudieran ejercer los predicadores, parece más plausible pensar que la base de esta estructuración familiar proceda originalmente del mundo indígena. Incluso aunque la poligamia estuviese permitida, es probable que los hombres de una sociedad relativamente modesta en lo material no encontrasen fácil sostener a varias mujeres y la numerosa descendencia que de esta situación podría resultar. Los sermones cristianos bien hubieran podido contribuir a fortalecer este estado de cosas, pero parece excesivo pensar que lo creasen. Entendemos así que esta monogamia es más un rasgo autóctono que aportación europea y que con él se termina de dibujar una sociedad indígena de comienzos del siglo XVII que conservaba aún entonces una gran parte del legado de sus ancestros y en la que las influencias españolas habían penetrado sólo de forma muy liviana.

Sobre este desarrollo histórico de relativa continuidad social y cultural y de lenta hispanización, la esclavitud incidió de una forma brutal. Sus efectos no son difíciles de suponer, pero podemos ahora documentarlos sobre la experiencia personal de los esclavos capturados por Barrera Chacón:

1. Privación de libertad, de hecho y de derecho.

2. Desarraigo, antes comentado. Personas nacidas al norte del archipiélago de Chiloé o en la actual región de Los Lagos fueron arrancadas de las tierras donde nacieron y llevadas por la fuerza al Chile central y quizás incluso a Perú.

3. Desestructuración social, puesto que en el traslado y en la venta posterior fueron inevitablemente separados individuos que pertenecían a un mismo cacicazgo y una misma familia.

Veámoslo con algún pormenor.

Los esclavos que desde la periferia chilota llegaron a los espacios nucleares del Chile Colonial allá por abril de 1611 debieron contarse entre 250 y 300 . El gráfico que hemos reconstruido individualiza a 278 , pero sería muy ingenuo conceder a esta cifra una exactitud completamente fiable. Un arco numérico como el antes propuesto es la contabilización más prudente por la que puede apostarse. Como puede verse con claridad, se dan en ellos todas las tipologías posibles: adultos de ambos sexos, ancianos, niños... Nadie escapó a este negocio brutal. 
Las redes sociales que participaron en este traslado de mercancía humana no son fáciles de reconstruir, aunque sin duda giraron en torno al maestre don Pedro de la Barrera, miembro de la élite social chilena como hijo de don Gaspar de la Barrera y doña Luciana de Vergara y Silva. Creo que puede comprenderse la importancia económica que para un hombre como don Pedro podía tener el negocio de la esclavitud, ante la depreciación de la rentabilidad de las encomiendas ${ }^{16}$ y los exiguos ingresos que percibían (oficialmente) los militares chilenos ${ }^{17}$. Él ordenó las malocas que proporcionaron las piezas, fundamentalmente dos: la que hizo su subordinado el capitán Martín de Vega a Colotue en enero de 1611 (en la que cayeron algunas de las familias mejor documentadas, como las de Francisco Muymil, Domingo Maichen, Rodrigo Calbuen, Martín Maynam o Miguel Luculante) o la que él mismo lanzó sobre Cunco en marzo de 1610 (de la que provienen muchas de las familias, también bien localizadas, del cacicazgo de Pedro Quintoparay) ${ }^{18}$; él introdujo los esclavos en el mercado y siempre figuró como el principal responsable de toda la empresa, de ahí que Machado, cuando quiso enfrentarse a ella, se querellase con él mucho más directamente que con cualquier otro implicado.

Puede documentarse la estrecha vinculación con Barrera Chacón de algunas de las personas que participaron en el negocio. Gonzalo Martínez de Vergara, por ejemplo, importante transportista que trasladó algo más de 50 esclavos en el navío Nuestra Señora de la Candelaria, era un mestizo españolizado, tío de Barrera Chacón como hermanastro de su madre doña Luciana (no mestiza, pero sí ilegítima) ${ }^{19}$. Ginés de Lillo, receptor de ocho piezas, militar de línea dura y rico estanciero, era su cuñado ${ }^{20}$. De este modo, los esclavos traídos por Martínez de Vergara a Lillo nunca salieron del estricto ámbito de la familia del maestre de campo y seguramente nunca los vendieron, sino que aprovecharon su fuerza de

16 GóngORA DEl CAMPO, M. (1970). Encomenderos y estancieros. Estudios acerca de la constitución social aristocrática de Chile después de la Conquista, 1580-1660, Santiago: Editorial Universitaria. ZuÑIGA, J. P. (2002). Espagnols d'Outre-mer. Émigration, métissage et reproduction sociale à Santiago du Chili, au $17^{e}$ siècle, París: EHESS.

${ }^{17}$ VARgas Cariola, J. E. (1993). «Estilo de vida en el ejército de Chile durante el siglo XVII». Revista de Indias, 198, pp. 425-57.

18 Las patentes también dan alguna información, muy somera, sobre otras dos malocas: una a "Chayao" y otra a "Llanquilco".

19 ThAYER OJEDA. Formación de la sociedad chilena, II: nacido en 1570, hijo ilegítimo de Francisco Martínez, compañero de Pedro de Valdivia, y doña Mariana Pico de Plata, cacica de Chacabuco. Se casó con doña Teresa Ahumada, sobrina nieta de santa Teresa de Jesús.

${ }^{20}$ Así se afirma en el expediente que analizamos. Sobre este conocido personaje del Chile Colonial véanse sus memoriales en AGI, Chile, leg. 43, n. 13 y AGI, Chile, leg. 33, s.n. 
trabajo en las chacras propias. Ahora bien, este grupo no representa sino un mínimo porcentaje del volumen total de esclavos incluidos en la operación, que con total seguridad fueron destinados mayoritariamente a la venta.

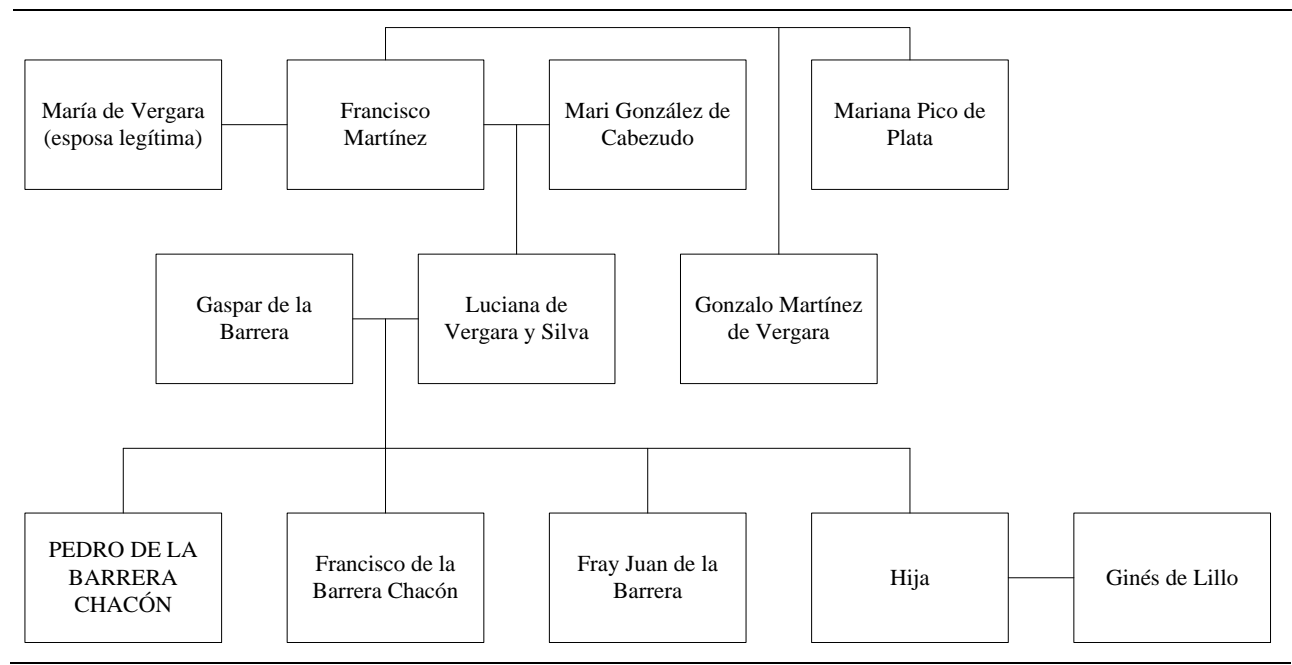

La Memoria de la gente e indios que vinieron..., principal fuente de información en este particular, nos descubre que en general el traslado conllevó la colaboración de personas que transportaron la mercancía y otras que las recogieron. ¿Quiénes eran estos hombres? Desgraciadamente, no hemos logrado hallar la personalidad que se esconde tras los nombres de la mayoría de los transportistas (Hernando de Andrada, Antonio Méndez, Alonso de Pineda, Simón Román, Juan de Alanís...) y, en consecuencia, no hemos podido discernir la relación que los une con el estamento militar que capturó originalmente los esclavos. ¿Eran otros miembros de la clientela de Barrera Chacón como Martínez de Vergara?, ¿lo eran acaso de otros oficiales y soldados participantes en las malocas?, ¿eran empresarios que habían comprados los esclavos a los militares y ahora esperaban revenderlos en el Chile central? Plausiblemente, todas o varias de estas opciones y otras posibles se simultanearían, pero de momento no hemos hallado el medio de documentarlas.

Entre los receptores de la mercancía también permanecen numerosas incógnitas, aunque afortunadamente muchos de ellos sean más fáciles de identificar. Por ejemplo, hay entre ellos militares bien conocidos como el maestre de campo Jerónimo Peraza o los capitanes Francisco Flores de Valdés y Diego de Venegas, eclesiásticos como el canónigo García de Torres, profesionales como el escribano Manuel de Toro o mercaderes-estancieros como Alonso del Campo Lantadilla. Algunos de ellos debieron ser directamente los compradores de los esclavos, 
aquellos para quienes éstos trabajarían, y otros, presumiblemente identificables entre los que más piezas recibieron, debieron recoger las piezas para revenderlas posteriormente. Ya hemos mencionado que, con casi total seguridad, éste fue el caso de Juan Pérez de Urasandi. En general, estos receptores parecen provenir de estratos bien situados en la sociedad española de Chile, aunque sin alcanzar el rango aristocrático de linajes como los Lisperguer o los Ríos. Lo que en ambos casos habría que determinar es cómo se establecieron las conexiones previas entre transportistas y receptores. En general, todavía queda por dilucidar globalmente los puntos de contacto en la cadena militares-transportistas-receptores, sólo reconstruible en algún caso muy concreto como el antes detallado de Barrera Chacón-Martínez de Vergara-Lillo.

Las partidas esclavistas en las que no figuraba ningún receptor previo debieron consignarse para una venta abierta en esos mercados chilenos ansiosos de mano de obra que con tanta maestría retratase Álvaro Jara ${ }^{21}$. Obviamente, el expediente del pleito apenas da información sobre estas ventas, sencillamente porque muchas de ellas, probablemente la mayoría, ni siquiera habían llegado a concretarse cuando Machado echó el peso de la ley sobre la empresa. Sin embargo, sí sabemos que la familia de un indio llamado Alonso quedó completamente descompuesta tras el desembarco: su mujer Jerónima fue vendida en Concón, su hijo Frasquillo en Valparaíso y su madre en Melipilla. Este caso, aunque aislado, es suficientemente ilustrativo de la profunda desestructuración de los cacicazgos y familias que pudo producir esta venta atomizada, en la que los compradores ya no eran necesariamente individuos relativamente bien posicionados socialmente como los receptores anteriormente reseñados, sino que pertenecían también a sectores sociales más humildes. Ejemplo paradigmático el de esa india Guele de la que se nos dice que la adquirió una negra liberta. Si a todo ello unimos las muertes que debieron producirse en las malocas y las arbitrariedades del traslado (en el que abundaron los niños menores de 10 años que viajaban completamente solos), podrá comprenderse la gravedad del impacto sobre los cacicazgos del sur del negocio de la esclavitud en todas sus fases -desde la expedición militar hasta la venta-. Sin duda, constituyó una profunda ruptura de su proceso histórico, seguramente en mucho mayor medida que el régimen de encomienda.

Este cuadro, ciertamente sombrío, no encierra toda la realidad. También formaron parte de la sociedad colonial hombres dispuestos a luchar por la justicia como Hernando Machado, cuya trayectoria personal conocemos bien gracias a la

${ }^{21}$ Jara. Guerra y sociedad. 
labor investigadora de Jesús Paniagua y $\mathrm{M}^{\mathrm{a}}$ Isabel Viforcos ${ }^{22}$. La preocupación por los derechos del indio chileno fue una constante en su vida, por lo que no sorprende su actuación en estas circunstancias. Durante el debate que sostuvo frente a los procuradores de Barrera Chacón en Santiago, especialmente frente a Ginés de Lillo, Machado defendió la teoría de que los indios de Valdivia y Osorno no habían participado en la gran rebelión contra los españoles, con quienes siempre habían convivido armoniosamente. Por tanto, no eran rebeldes a la Corona y, en tal caso, no se les podía aplicar la cédula de la esclavitud, que muy claramente especificaba que sólo podrían ser privados de su libertad aquellos indios que se levantasen en armas frente a la Monarquía y la Iglesia Católica. Como era de esperar, la defensa de Lillo se fundamentó en negar esa información y asegurar en contrapartida que los habitantes de las regiones maloqueadas sí participaron en la revuelta, de forma que cumplían todos los requisitos para ser esclavizados en caso de caer prisioneros de guerra.

Con las pruebas documentales por delante -declaraciones de testigos, certificaciones, listados...-, los oidores de la Audiencia dieron la razón a su fiscal mediante sentencia pronunciada en 3 de octubre de 1614. Doña Luciana de Vergara apeló ante el Consejo de Indias ${ }^{23}$, pero sus ministros ${ }^{24}$ confirmaron la resolución el $^{2}$ 6 de diciembre de $1619^{25}$. No sabemos hasta qué punto pudieron estas resoluciones desagraviar a los esclavos ni evitarles más sufrimientos, pero ambas constituyeron como poco un testimonio precioso de que hubo hombres e instituciones que se tomaron en serio las aspiraciones de justicia que residían en la retórica imperialista de la España Moderna.

Para terminar, nos gustaría destacar las siguientes ideas:

1. Las rutas de la trata esclavista en Chile Colonial articularon espacios de diversa funcionalidad. Hubo zonas de captación de piezas que se encontraron

22 PAniagua PÉReZ, J. y Viforcos Marinas, M. I. (1997). El humanismo jurídico en las Indias. Hernando Machado y su memorial sobre la guerra de Chile, Badajoz: Diputación.

${ }^{23}$ Paralelamente, envió a Madrid una información exponiendo sus cuitas, lo cual evidentemente formaba parte de una estrategia global que no surtió ningún efecto: AGI, Chile, leg. 41, n. 9; exp. de Luciana de Vergara, 1615. Su protagonismo durante las últimas fases del pleito deviene de la muerte de don Pedro y del traslado de Lillo a la frontera araucana.

${ }^{24}$ Felipe III comisionó el pleito a Pedro Marmolejo, Alonso Maldonado de Torres, Juan de Vilella, Juan de la Corte, Diego Lucio Lucero y Garci Pérez de Araciel, por real provisión de 19 de febrero de 1616 (fols. 165-166). Éstos lo admitieron a trámite el 12 de julio: AGI, Escribanía, leg. 955, s.n. El pleito también señala este dato en fol. 167.

${ }^{25}$ AGI, Escribanía, leg. 955, s.n.; sentencia definitiva del Consejo, Madrid, 6 de diciembre de 1619. 
fundamentalmente en las fronteras de guerra, pero no sólo en la araucana, sino también la huilliche ${ }^{26}$, cuya importancia evidencia el expediente que hemos analizado. Los mercados se ubicaron preferentemente en el Chile nuclear, aunque muy probablemente superaron las fronteras del Reino y alcanzaron hasta Perú.

2. La esclavitud poseyó un potencial destructor muy superior al de la encomienda, aplicada a una sociedad superficialmente cristianizada y organizada en torno a los cacicazgos y sobre la célula básica de la familia, que podría caracterizarse como mononuclear, patriarcal y generadora de una prole que aparece compuesta por dos o tres hijos en los casos conocidos.

3. Las redes del negocio esclavista integraron a militares, comerciantes transportistas y compradores, si bien los intrincados nexos de unión entre estos colectivos no siempre son fáciles de precisar. El interés por participar de una forma u otra en la trata se explica desde varias perspectivas: la exiguiidad de las soldadas militares, la depreciación económica de las encomiendas o la necesidad de mano de obra, que podía escasear o resultar útil no sólo a encomenderos y estancieros destacados, sino también a gentes más modestas. Los compradores parecen haber pertenecido a sectores sociales diversos y no sólo a las élites de la Colonia.

4. La práctica de la trata esclavista legalizada entrañaba un debate en el que los posicionamientos fundamentales giraban en torno a la posibilidad de demostrar que las piezas procedían de provincias indígenas rebeldes, condición que la cédula de la esclavitud exigía con tal claridad que nadie pudo interpretar con doblez. La polémica comenzaba desde el momento en que hubo personas deseosas de combatir el negocio esclavista más descarnado. Y las hubo, aunque fuesen pocas.

Estas consideraciones no pretenden en modo alguno distinguirse como conclusiones cerradas, sino como hipótesis por verificar con investigaciones futuras sobre el tema. La historia de la esclavitud legal de indios en el Chile del siglo XVII está aún por escribirse y es obvio que no puede hacerse cabalmente sólo con los datos de este pleito.

\footnotetext{
${ }^{26}$ Distinguimos entre frontera huilliche y araucana siguiendo la nomenclatura acuñada en Urbina Carrasco. La frontera de arriba.
} 